\title{
Towards Harnessing Wireless Sensor Networks for Supporting the Development Process in Iraq
}

\author{
Murtadha M. N. Aldeer ${ }^{\star \dagger}$, Richard E. Howard ${ }^{\star}$, Richard P. Martin ${ }^{\star}$, Khalil Alkadhimi ${ }^{\ddagger}$ and Latifah Munirah Kamarudin ${ }^{\S}$ \\ ${ }^{\star}$ WINLAB, Rutgers The State University of New Jersey, North Brunswick, NJ 08902, USA \\ ${ }^{\dagger}$ State Co. for Internet Services, Ministry of Communications, P O Box 773, Basrah, Iraq \\ ${ }^{\ddagger}$ School of Engineering, University of Portsmouth, Portsmouth, PO1 3DJ, UK \\ ${ }^{\S}$ Centre of Excellence for Advanced Sensor Technology, Universiti Malaysia Perlis, Perlis, Malaysia \\ ^maldeer@winlab.rutgers.edu, reh@winlab.rutgers.edu,rmartin@cs.rutgers.edu \\ ${ }^{\ddagger}$ khalil.alkadhimi@ port.ac.uk, ${ }^{\S}$ latifahmunirah@unimap.edu.my
}

\begin{abstract}
Iraq is a developing country and so its developmental process has been stymied and often stalled, one obstacle is the lack of applying the latest technological innovations and instead relying on traditional methods. Wireless Sensor Networks (WSNs) is an emerging technology that have been utilized to make many improvements. This paper serves as a tutorial that aims at identifying some of the current WSNs applications that can be harnessed for aiding the development process in Iraq. It also discusses the advantages of wireless sensors in the context of Iraq and tackles the obstacles that may prevent their implementation. Finally, the paper presents a WSN system for salinity monitoring in the Iraqi rivers as it is one of the major issues in this country.
\end{abstract}

\section{Keywords- WSNs, Iraq, Sensors, Applications.}

\section{INTRODUCTION}

Since the second Gulf War in 2003, Iraq has been is in an on-going developmental process in virtually every sector with the goal of rebuilding its infrastructure and reforming its civic institutions. However, consecutive Iraqi governments have struggled in achieving these goals due to many reasons, among which is the absence of incorporating well-established technological innovations to support the development process. Nowadays, most health care, environmental monitoring, industrial, intelligent transportation and other systems relay on technologies such as the Information and Communications Technology (ICT). In light of the challenges that face Iraq, we motivate the use of an emerging ICT solutions that narrow the gap between the physical world and the computers for supporting the development process in Iraq, that is WSNs [1]. A WSN is a gathering of spatially distributed sensor nodes that can be deployed in physical environments where they operate unattended [2]. A sensor node is a cheap, small, intelligent and low power device that has the ability to perform sensing, computations and wireless communications operations. Moreover, there is at least one sink node which is an energy-rich computing system that coordinates the network, collects incoming events from the distributed sensor nodes, and transmits the sensed events data to a remote server that is mostly located in the external world. The sink node may relay on a gateway node that supports other communication network technologies such as: Satellite, GPRS, WiFi or Ethernet to communicate with the server. In addition to their distinctive characteristics, the integration of WSNs with other emerging technologies such as Software Defined Networks (SDN) [3] would make them a very useful backbone networks for supporting the development process by enabling a diversity of applications in all life sides [1], [4]-[7]. This paper can be unfolded in two main sections. The first discusses several WSNs application domains that are beneficial for supporting Iraq in the on-going development process and the feasibility of implementing them. The second section proposes a design of a WSN-based system for tracking changes in salinity trends in Iraq's rivers that is a work in progress.

\section{Potential Application Domains of WSNs in IRaQ}

Iraq is a rich but still developing country that is striving to attain the Millennium Development Goals. Hence, most life sectors in Iraq, such as the security, industry and environment, need to be rehabilitated and redeveloped. Thus, we can say, without exaggeration that Iraq can benefit from the potential applications of an outstanding technology such as WSNs to instrument the development of various governmental, industrial, military and civilian aspects. In this section we narrow the problems that are currently exist in Iraq. We only discuss the most important scenarios and motivate the WSNs applications that can be applied. Nevertheless, the applicability of WSNs needs a reassessment to consider typical requirements and challenges in the context of Iraq.

\section{A. Military and Security Applications}

The critical security situation in Iraq is the main factor that negatively impacts the on-going development process. Iraq has been in conflict with terrorism for more than a decade. Indeed, terrorist groups are scattered in Iraq, where some of them are entering the country throughout neighboring countries. Those groups are imposing an incessant risk factor to the populace of the country, as can be evinced by the many almost daily bombing operations, attacks against many governmental facilities, targeting official representatives and people, destroying Iraq infrastructure, erasing the cultural heritage of Iraq, etc. Thousands of people have perished, and the entire infrastructure have crumbled. Nevertheless, Iraqi military and 
police forces are fighting these hostile groups with a goal of identifying and zeroing in on the terrorism spots. Based on the aforementioned considerations, innovation in efficient military systems is a fundamental pillar for the success of those operations. In recent years, it has been proved that employing technology such as WSNs can be a fundamental role for supporting military and security operations and demands [8]. WSNs's purposes in this area are different; in this section some that are useful for the critical case of Iraq are reported.

Sadly, Iraqi soldiers and police forces are being attacked and killed by terrorists on a daily basis. They have no responsibility only for being the hand of government in peace dissemination in Iraq. For example, in June 2014, terrorist groups have attacked a military base in Salahuddin city that resulted in capturing and executing 1,700 soldiers at least. That is Camp Speicher Massacre. Based on that, monitoring the Iraqi security forces should be an important issue especially during battlefield and security operations, at least, for the aim of reducing such mortalities. Recent studies showed that wireless body area sensor networks (WBASNs) [9] can play a major role in monitoring human's health and location tracking. WBASNs use relatively cheap and mobile wireless nodes that are equipped with sensor(s) which make them an assistive solution to design decision support systems that would be used by military operations managers to efficiently manage and track the troops that participate in the battlefield operations.

Another important application of this domain that the police forces in Iraq may make use of is WSNs-based explosive detection systems. Bombers, roadside bombs and car bombs are reaping the souls of tens of Iraqi people each day in Iraq. Even Iraq is spending billions of dollars for arming the military and security forces; however, this has not succeeded in stopping these attacks. Failure of stopping such attacks can be attributed to reasons such as the lack of smart explosive detection devices to be equipped to the Iraqi official forces and the fake detection devices those are in use. Wireless sensing technology would be a cheap and effective solution in such a scenario. It can be used for the detection and tracking the explosive materials in public places such as streets, train stations, airports, shopping centers, etc. Terrestrial and mobile nodes that relay on metal detectors and chemical sensors can be used to detect these bombs [10].

\section{B. Industrial Applications}

In Iraq, the economic development has been groaning under the perpetual faulty power-grid system that spans the entire country. Uneven power distribution, power outage, and the instability have almost always plagued every industry in Iraq. Post 2003 war, Iraq electricity network is on-going rehabilitation process [11]. However, old fashion solutions will not help in meeting the increasing demands on the power grid in the current era. A new power-grid system propped up by appropriate WSNs can mitigate faults and enhance the operation and distribution of electricity. A wide variety of wireless sensors can be deployed for monitoring which might include power generation, transmission lines [12], substations and transformers [13], distribution and meter reading [14]. A correct deployment of the WSNs in a power-grid system can yield in a real-time and accurate statistics about the status of the entire power grid, which prompts better management. Moreover, the user's power consumption, bill distribution and flow cutting and connection can all be maintained by using appropriate WSNs [15].

Iraq's oil is the backbone of its economy. Thus boosting oil production is always a goal for the Iraqi government. As stated in [16], achieving such a goal will involve overcoming numerous obstacles by taking the advantage of the latest technological developments in several process areas including: exploration, extraction, refinement, and transportation pipelines. Experiences of utilizing WSNs technology in such fields revealed the importance and idealistic of this technology. The advantages that may yield from using WSNs in this oil field can be attributed to the usage of sensor nodes that are long in life and cable-less, flexibility, easy deployment and maintenance and timely information delivery that meet the requirements. It is worth to mention that upgrading other industrial sectors in Iraq is an important demand since these would be other sources that feed Iraq's economy especially when the oil prices fall.

\section{Environmental Applications}

In Iraq, there are many factors that pollute the air and decrease its quality, which in result cause various pulmonary problems. Among these are: population increase, high traffic levels, oil refineries, industrial plants and power generation stations [17]. Static wireless monitoring stations integrated with multi-gas sensors may be employed for air pollutants monitoring purposes. These stations can be distributed in an areas of interest, for example in the oil and gas cities of Iraq, such as Basrah and Kirkuk to acquire air pollutants measurements and air quality level [18]. The stations monitor multi pollutants gases and transmit the sensed data to a remote server. Live data can be available for the public by streaming them onto the web from which the position of the monitoring stations can be viewed as well. Such a system can support the Iraqi Ministry of environment in its endeavor for monitoring the environment and identifying the critical factors.

Iraq is endowed with two main rivers that traverse its lands from the north to the south namely the Tigris and the Euphrates. The two rivers confluence to form Shatt Al-Arab River that traverses the city of Basrah to discharge in the Gulf. These Rivers control the water resources in Iraq and they form the main source of drinking water for Iraqi citizens. Recent studies have shown that the water quality of these resources has deteriorated significantly due to the severe suffering from some factors among which the salinity is dominant [19]-[21]. This presents a real crisis to the people, ecosystems and agricultural activities in Iraq. Hence, careful and real-time monitoring of these water banks is an important factor that helps in solution proposals for preserving the environment of these water sources and mitigating the crisis. Iraqi environmentalists depend on the methodology of manually gathering a number of water samples from chosen sampling points to study the chemical suite [22], [23]. Usually results are fed to a computer program to generate some statistics. This methodology requires a lot of effort and is prone to errors. Aiming to preserve the fresh water quality; 


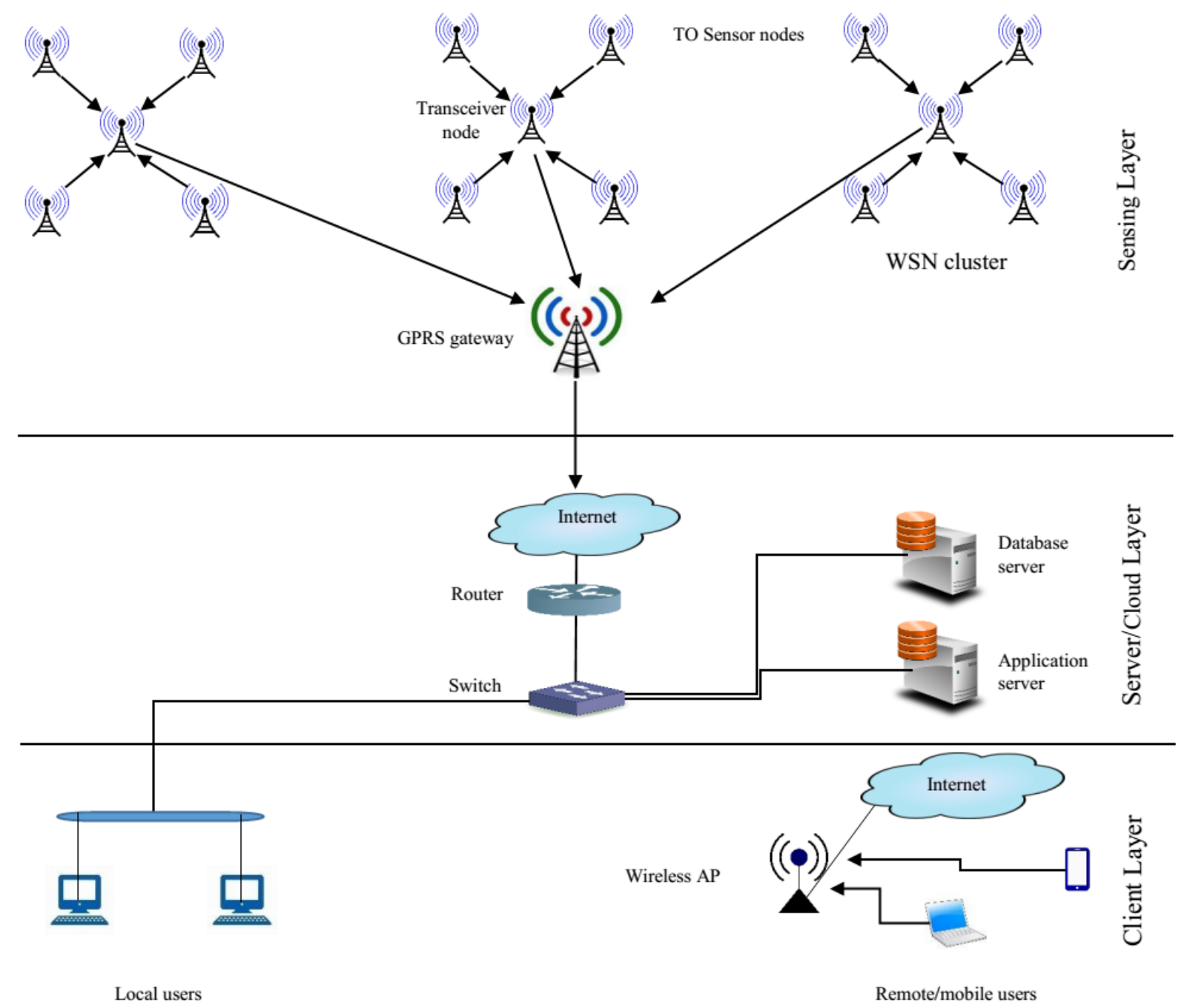

Fig. 1. A schematic view of the proposed system architecture.

in-line chemical monitoring of these water banks should be carried out. Water quality monitoring is an important class of WSNs applications [24]. In the next section an overview of a design of WSN-based system for salinity monitoring in Iraq is given, that is a work-in-progress.

\section{A WSN FOR SALINITY MONITORING}

\section{A. Motivation}

The increasing levels of salinity in the Iraqi rivers poses a real threat to the life in Iraq [19]-[21], [25]. As Yoneki [26] stated "We need to better understand the nature and environments, so that our lives improve", this section proposes a design of a smart data gathering system using network of wireless sensors. Few approaches have recently utilized WSNs for salinity monitoring [27]-[29]. Our proposed system's architecture is illustrated in Fig. 1 which uses a hybrid network architecture to gather the salinity level readings and relay them to a remote server for analysis and presentation. Similar to most
WSNs systems, the computing system in our design employs a 3-layer architecture.

\section{B. Proposed System}

1) Sensing Layer: which hosts the sensor nodes that are distributed in the physical world. Our design relays on the idea of using two types of sensor nodes, transmit-only (TO) [30], [31] nodes and transceivers, and that is where its hybridity comes from. TO sensor nodes are responsible for sampling some data from the environment and periodically transmitting them to the transceivers via a one-hop communication. The notion of using TO nodes in such a system is due to the fact that data are only propagate from the sensing nodes to the transceiver node and this is a common case in environmental and ecological applications of WSNs [32]. In addition, TO nodes have several advancements over the transmit-receive nodes from the cost and power consumption points of view [31], [33].

A capacitive sensor [34], [35] can be used to determine the 
characteristics of water samples as the value of the capacitance is measured and compared. The capacitive sensor uses two parallel conducting plates that are separated by a relatively short gap. When this gap is filled with a dielectric (in our case the water), there exist an electric field between the plates given that one of the plates is voltage fed [34]-[36]. Hence, our capacitive sensor topology works under the principle of fringing capacitance. Indeed, the capacitance depends on the dielectric material that fills the gap.

For the experiments, a prototype has been built for this reason and tested via lab experiments at WINLAB of Rutgers University. We use the PIP tag that has been developed in WINLAB of Rutgers University [37]. PIP tag is based on a 16-bit MSP430G2553 MCU and a Chipcon CC1150 RF transmitter, both from Texas Instruments. The RF transceiver is tuned to broadcast at $900 \mathrm{MHz}$ frequency [38]. The sensor node also embeds a 512 Bytes RAM and 16 KB Flash ROM and a $20 \mathrm{~mm}$ lithium coin size battery as a power source [37], [39], [40].

Fig. 2 shows the PIP-tag and the sensor. The sensor is built of a $1 \times 2 \mathrm{~cm}$ plates that are separated by $1 \mathrm{~mm}$ gap and an in-line resistor. The plates have been coated by $1 \sim 2 \mu \mathrm{m}$ of polymer. The capacitance value is measured by measuring the RC time constant that determines the time required for charging it from $0 V$ to a given value. Measurement method may base on the charge/discharge technique where the time constant $(\tau)$ can be obtained from solving the equation below [41]:

$$
V c=V C C\left[1-\exp ^{-(\tau / R C)}\right]
$$

Where $R$ is the the resistor connected in line with the capacitor that have $C$ capacitance. $V c$ and $V C C$ are the voltage across the capacitor and the source voltage, respectively. Hence, this equation can be obtained when substituting the current across the capacitor as the derivative of its charge with respect to time. A sample result of the measurement generated by our system showed that the capacitance of air was around $14 \mathrm{pF}$ while the tap water capacitance was in the range 258 261 $p F$.

Transceiver nodes are similar to the TO nodes in their design; but more powerful. Although, they do not incorporate sensors. They contain full-duplex radios (i.e an RF transmitter and a receiver), and they are responsible for collecting the information form the transmit-only nodes and relaying it to a central
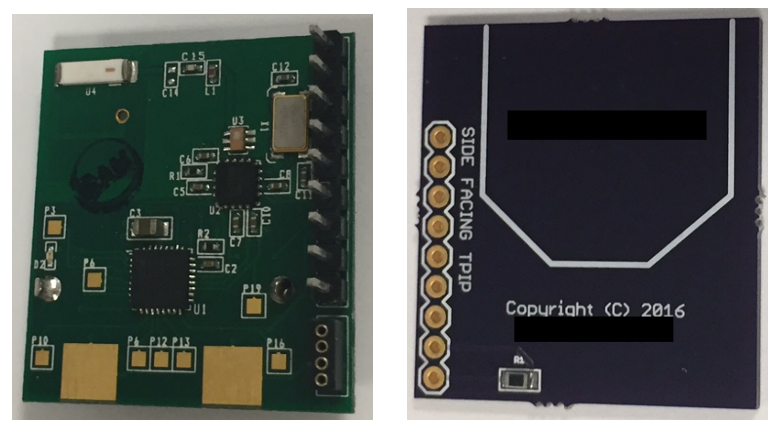

Fig. 2. A view of the PIP Tag and the capacitive sensor. server via a nearby GPRS gateway. It is worth mentioning that the transceiver nodes should be richer in power as compared to the TO nodes as they form the clusters' heads in our design. As such, taking into consideration the climate of Iraq that is mostly clear and sunny year round; transducers such as solar cells can be equipped to power the transceiver nodes in such an application.

The notion behind choosing GPRS as the mean for data delivery is based on the fact that most monitoring points will be in rural areas where only GSM/GPRS service is available. Finally, it is suggested to distribute the sensor nodes as clusters to form a ubiquitous-like computing system, where the nodes can be attached to the bottom of a buoy that floats in the water and thus they will be responsible for monitoring a specific spot of the river [26].

2) Server/Cloud Layer: mainly hosts a database server and an application server. The GPRS gateway strips the data from the arriving packets and communicates them to the server via the Internet. Received data are stored in the database server where they can be classified and then fed to the application server for user friendly presentation. As such, the server/cloud layer provides a communication tunnel between the end users and the monitored site(s) and ensures that our system will have a global presence through the Internet.

3) The Client Layer: offers the end users a friendly representation and visualization for the data collected from each monitoring point via the users preferred device.

\section{OBSTACLES}

WSNs have been almost applied in all life aspects. However, each application depends on the environment applied in and thus there are always obstacles to be addressed and overcome before the real deployment [42]. The main obstacles that need to be addresses before the implementation of WSNs projects in Iraq may include:

-Standardization of the ICT sector in Iraq is not yet completed. As such, proposing an ICT policy for Iraq [43] is an important step since it strongly participates in supporting the transformation and development process by the authorization of telecommunications regulations that govern the work in the ICT sector in this country.

-From the infrastructure point of view, it is believed that the majority of the WSNs-based solutions reported in this paper can be successfully implemented when applied in Iraq. This is due to the fact that most WSNs-based solutions rely on other wireless networks (such as GSM/GPRS, Satellite, etc.) as a backbone to deliver the collected information to the network center. However, the need for a robust ICT infrastructure that relays on fast and reliable communication technologies is required for supporting the scalability, robustness, fault tolerance and minimization of deployment cost that are known characteristics of the WSNs.

-Electrical power supply has been always a great concern in Iraq. However, ICT projects demands faulty tolerant resources of electrical power supply, mainly to run the system at the server/cloud layer. As such cretin steps need to be taken in this regard to overcome this dilemma. One approach to managing 
electrical grid reliability issues is to use containerized datacenters with solar augmented power. The stored solar power can be used to help ride-out outages.

-As any other developing country, there is a lack of experienced staff for administrating and implementing such projects in Iraq. To overcome this, there is an urgent need for collaboration between people from academia, industry, community, politicians, decision makers and international partners.

\section{Conclusion And Future Work}

In this paper, we tackled only few WSNs applications that are beneficial in the context of a developing country like Iraq. Also, a WSNs-based system for salinity measurement that relies on transmit only sensor nodes, has been proposed. In future, our salinity sensor will be calibrated for further measurements and its performance against robustness and operational lifetime will be evaluated such that the design could be enhanced for the aim to meet our application requirements.

\section{REFERENCES}

[1] M. Zennaro, B. Pehrson, and A. Bagula, "Wireless sensor networks: a great opportunity for researchers in developing countries," in Proc. of WCITD2008 Conf., vol. 67, Pretoria, 2008.

[2] M. Matin and M. Islam, Overview of wireless sensor network. INTECH Open Access Publisher, 2012.

[3] L. Galluccio, S. Milardo, G. Morabito, and S. Palazzo, "Sdn-wise: Design, prototyping and experimentation of a stateful sdn solution for wireless sensor networks," in 2015 IEEE Conf. on Computer Communications (INFOCOM), Hong Kong, 2015, pp. 513-521.

[4] E. Basha and D. Rus, "Design of early warning flood detection systems for developing countries," in Information and Communication Technologies and Development, 2007. ICTD 2007. International Conference on, Dec 2007, pp. 1-10.

[5] J. Panchard, S. Rao, T. V. Prabhakar, H. S. Jamadagni, and J. p. Hubaux, "Common-sense net: Improved water management for resource-poor farmers via sensor networks," in Int. Conf. on Information and Communication Technologies and Development, May 2006, pp. 22-33.

[6] T. Arampatzis, J. Lygeros, and S. Manesis, "A survey of applications of wireless sensors and wireless sensor networks," in Proceedings of the 2005 IEEE Int. Mediterrean Conf. on Control and Automation Intelligent, June 2005, pp. 719-724.

[7] M. Aldeer, "A summary survey on recent applications of wireless sensor networks," in IEEE Student Conf. on Research and Development (SCOReD), Putrajaya, 2013, pp. 485-490.

[8] M. P. Durisic, Z. Tafa, G. Dimi, and V. Milutinovi, "A survey of military applications of wireless sensor networks," in 2012 Mediterranean Conference on Embedded Computing (MECO), Bar, June 2012, pp. 196-199.

[9] A. Nadeem, M. A. Hussain, O. Owais, A. Salam, S. Iqbal, and K. Ahsan, "Application specific study, analysis and classification of body area wireless sensor network applications," Comput. Net., vol. 83, pp. $363-$ 380, 2015.

[10] S. Simi and M. V. Ramesh, "Real-time monitoring of explosives using wireless sensor networks," in Proc. of the 1st Amrita ACM-W Celebration on Women in Computing in India, Coimbatore, 2010, p. 44.

[11] M. Reda, N. Saied, A. Khaldi, M. Abdul-Hussain, and A. Ekwue, "Iraq electrical power infrastructure-past, present and future developments and expectations," in IEEE PES Power Systems Conf. and Exposition (PSCE'06), Atlanta, GA, 2006, pp. 1792-1795.

[12] B. Fateh, M. Govindarasu, and V. Ajjarapu, "Wireless network design for transmission line monitoring in smart grid," IEEE Trans. Smart Grid, vol. 4, no. 2, pp. 1076-1086, 2013.

[13] A. Nasipuri, R. Cox, J. Conrad, L. V. der Zel, B. Rodriguez, and R. McKosky, "Design considerations for a large-scale wireless sensor network for substation monitoring," in 2010 IEEE 35th Conference on Local Computer Networks (LCN), Denver, Colorado, Oct 2010, pp. 866873.

[14] V. C. Gungor, B. Lu, and G. P. Hancke, "Opportunities and challenges of wireless sensor networks in smart grid," IEEE Trans. Industrial Electronics, vol. 57, no. 10, pp. 3557-3564, 2010.
[15] B. Aghaei, "Using wireless sensor network in water, electricity and gas industry," in 3rd Int.l Conf. on Electronics Computer Technology (ICECT), vol. 2, Kanyakumari, 2011, pp. 14-17.

[16] M. R. Akhondi, A. Talevski, S. Carlsen, and S. Petersen, "Applications of wireless sensor networks in the oil, gas and resources industries," in 24th IEEE Int. Conf. on Advanced Information Networking and Applications (AINA), Perth, WA, 2010, pp. 941-948.

[17] A. A. Z. Douabul, S. S. Al Maarofi, H. T. Al-Saad, and S. Al-Hassen, "Gaseous pollutants in basra city, iraq," Air, Soil Water Research, vol. 6, p. 15, 2013.

[18] A. Kadri, E. Yaacoub, M. Mushtaha, and A. Abu-Dayya, "Wireless sensor network for real-time air pollution monitoring," in 1st Int. Conf. on Communications, Signal Processing, and their Applications (ICCSPA), Feb 2013, pp. 1-5.

[19] G. R. Gibson, J. B. Campbell, and C. E. Zipper, "Sociopolitical influences on cropland area change in iraq, 2001-2012," Appl. Geography, vol. 62, pp. 339-346, 2015.

[20] K. A. Rahi and T. Halihan, "Changes in the salinity of the euphrates river system in iraq," Regional Environmental Change, vol. 10, no. 1, pp. 27-35, 2010.

[21] A. D. Abdullah, I. Masih, P. van der Zaag, U. F. Karim, I. Popescu, and Q. A. Suhail, "Shatt al arab river system under escalating pressure: a preliminary exploration of the issues and options for mitigation," Int. J. of River Basin Management, vol. 13, no. 2, pp. 215-227, 2015.

[22] E. A. M. Salah, A. M. Turki, and E. M. Al-Othman, "Assessment of water quality of euphrates river using cluster analysis," J. Environ. Prot., vol. 3, no. 12, p. 1269, 2012.

[23] M. S. Moyel, "Assessment of water quality of the shatt al-arab river, using multivariate statistical technique," Mesopotamia Environmental J., vol. 1, no. 1, pp. 39-46, 2014.

[24] G. Xu, W. Shen, and X. Wang, "Applications of wireless sensor networks in marine environment monitoring: A survey," Sensors, vol. 14, no. 9, pp. 16932-16954, 2014.

[25] A. D. Abdullah, U. F. A. Karim, I. Masih, I. Popescu, and P. V. der Zaag, "Anthropogenic and tidal influences on salinity levels of the shatt al-arab river, basra, iraq," Int. J. of River Basin Management, vol. 14, no. 3, pp. 357-366, 2016.

[26] E. Yoneki, "Evolution of ubiquitous computing with sensor networks in urban environments," in Ubiquitous Computing Conf., Metapolis and urban Life Workshop Proc., Tokyo, 2005, pp. 56-59.

[27] L. Parra, S. Sendra, J. Lloret, and J. J. Rodrigues, "Low cost wireless sensor network for salinity monitoring in mangrove forests," in Proc. IEEE SENSORS, 2014, pp. 126-129.

[28] L. Parra, E. Karampelas, S. Sendra, J. Lloret, and J. J. Rodrigues, "Design and deployment of a smart system for data gathering in estuaries using wireless sensor networks," in Int. Conf. on Computer, Information and Telecommunication Systems (CITS), Gijon, 2015, pp. 1-5.

[29] L. Parra, V. Ortuño, S. Sendra, and J. Lloret, "Water conductivity measurements based on electromagnetic fields," in Proc. of the First Int. Conf. on Computational Science and Engineering (CSE13), 2013, pp. 6-8.

[30] B. Firner, "Transmit only for dense wireless networks," Ph.D. dissertation, Rutgers University-New Brunswick, 2014.

[31] B. Blaszczyszyn and B. Radunovic, "Using transmit-only sensors to reduce deployment cost of wireless sensor networks," in The 27th IEEE Conf. on Computer Communications (INFOCOM), April 2008, pp. 18761884.

[32] C. Huebner, R. Cardell-Oliver, S. Hanelt, T. Wagenknecht, and A. Monsalve, "Long-range wireless sensor networks with transmit-only nodes and software-defined receivers," Wireless Commun. Mobile Comput., vol. 13, no. 17, pp. 1499-1510, 2013.

[33] P. Parsch, A. Masrur, and W. Hardt, "Designing reliable home-automation networks based on unidirectional nodes," in Proceedings of the 9th IEEE Int. Symposium on Industrial Embedded Systems (SIES 2014), Pisa, June 2014, pp. 88-95.

[34] R. Puers, "Capacitive sensors: When and how to use them," Sensors and Actuators A: Physical, vol. 37, pp. 93 - 105, 1993.

[35] E. Terzic, J. Terzic, R. Nagarajah, and M. Alamgir, "Capacitive sensing technology," in A Neural Network Approach to Fluid Quantity Measurement in Dynamic Environments. Springer, 2012, pp. 11-37.

[36] M. Heidari and P. Azimi, "Conductivity effect on the capacitance measurement of a parallel-plate capacitive sensor system," African Phys. Rev., vol. 4, pp. 135-143, 2010.

[37] B. Firner, S. Medhekar, Y. Zhang, R. Howard, W. Trappe, P. Wolniansky, and E. Fenson, "Pip tags: Hardware design and power optimization," in 
In Proceedings of the Fifth Workshop on Embedded Networked Sensors (HotEmNets), Charlottesville, VA, April 2008.

[38] B. Firner, C. Xu, R. Howard, and Y. Zhang, "Multiple receiver strategies for minimizing packet loss in dense sensor networks," in Proceedings of the Eleventh ACM International Symposium on Mobile Ad Hoc Networking and Computing (MobiHoc '10), 2010, pp. 211-220.

[39] R. S. Moore, B. Firner, C. Xu, R. Howard, R. P. Martin, and Y. Zhang, "It's tea time: Do you know where your mug is?" in Proceedings of the 5th ACM Workshop on HotPlanet (HotPlanet '13), 2013, pp. 63-68.

[40] W. Trappe, R. Howard, and R. S. Moore, "Low-energy security: Limits and opportunities in the internet of things," IEEE Security Privacy, vol. 13, no. 1, pp. 14-21, Jan 2015.

[41] A. H. Robbins and W. C. Miller, Circuit analysis: Theory and practice. Cengage Learning, 2012.

[42] B. Rashid and M. H. Rehmani, "Applications of wireless sensor networks for urban areas: A survey," J. Netw. Compu. Appl., vol. 60, pp. $192-$ 219, 2016.

[43] H. Alyasiri and N. Abdulbaqi, "Proposed policy for iraqi ict sector (part i)," in 2012 Int. Conf. on Future Communication Networks (ICFCN), Baghdad, April 2012, pp. 129-134. 